التأثير المضاد لبكتيريا الزبادي التقليدي والداعم للحيوية ببكتيريا البيفيدو تجاه بكتريا السالمونيلا

$$
\text { مطلق بن محمد العتيي } 1
$$

التقليدي بجرعة ـ ه او ه . . ه باخلية لكل جرام زبادي على التوالي.

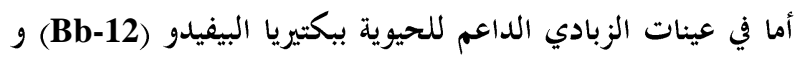
(Bb-46)

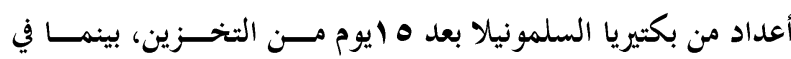

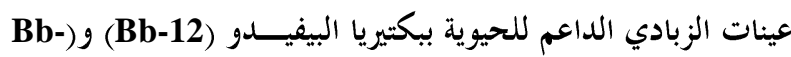

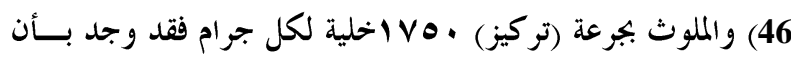

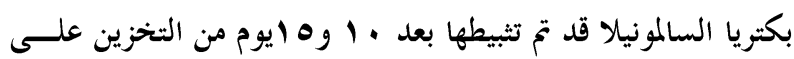

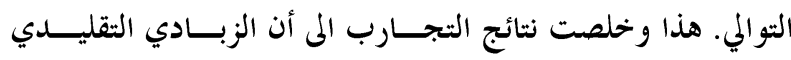

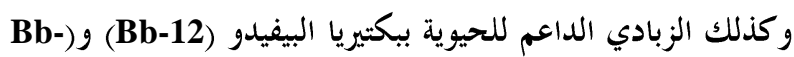

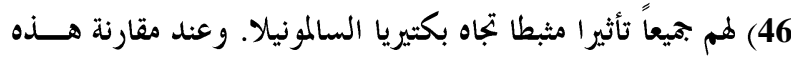

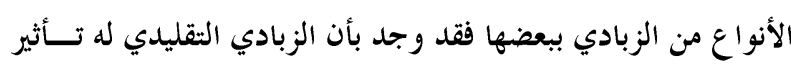

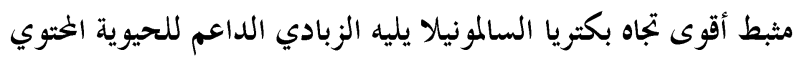

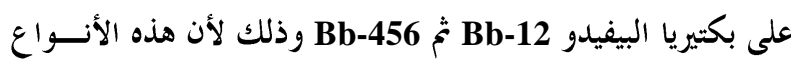

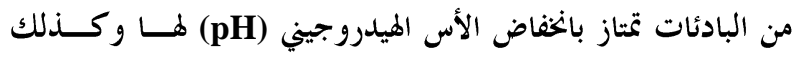
إفرازها لكميات من الأحماض العضوية ذات الفعل المثبط للبكتيريا التي

قد تلوث هذه المنتجات.

\section{المقدمة المشكلة البحثيـــة}

تعتبر الألبان المختمرة من أهم المنتجات اللبنية التي يرغبها قطاع

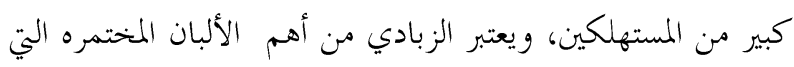

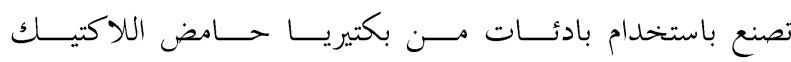
Streptococcus thermophilus \&Lactobacillus delbrueckii subsp. bulgaricus

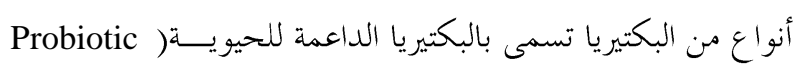

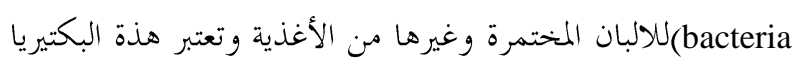

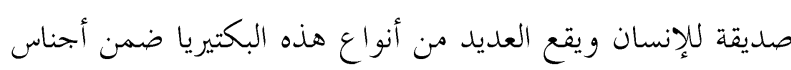
Lactobacillus \&Bifidobacterium

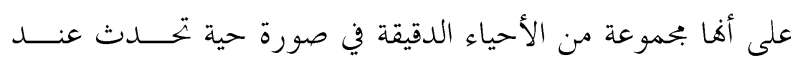

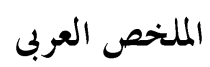

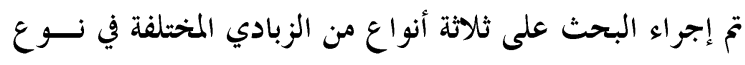
البادئ المستخدم حيث لقحت جميع عينات الزبادي باستخدام بكتيريا

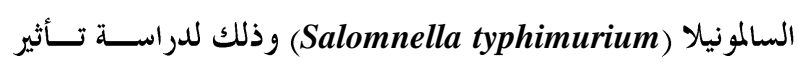

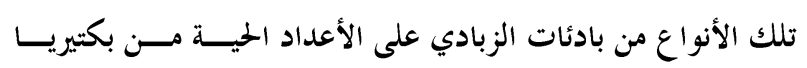

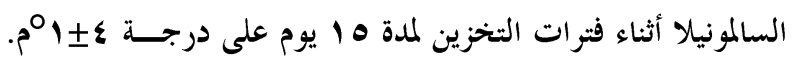
وقد تم تقدير الــ (pH) والأحاض العضوية (اللاكتيك والخليك) في جيع عينات الزبادي. وقد وجد أن قيم الــ (pH) قد سجلت انخفاضــاً في عينــات

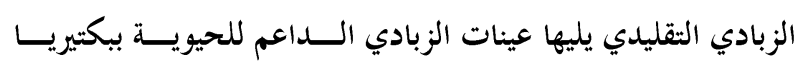
البيفيدو (Bb-12) ثم (Bb-46). كما أظهرت النتائج احتواء عينات

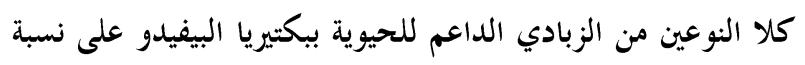

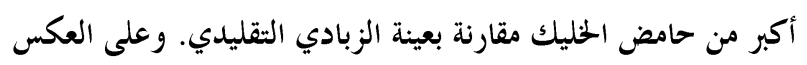

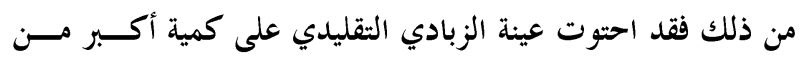

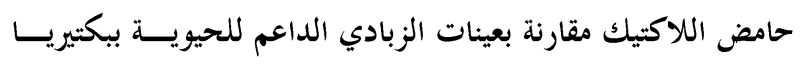

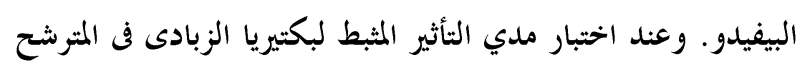

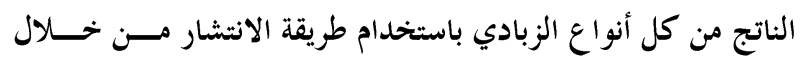
القرص الورقي وجد أن بكتيريا الزبادي التقليدي له تأثير مثبط أكبر التبري

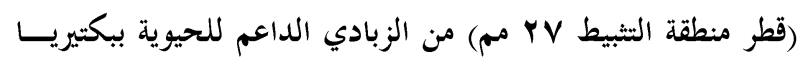

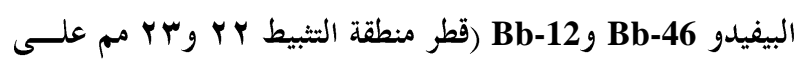
التوالي) تجاه بكتيريا السالمونيلا. وعند أجراء تلويث عينات الزبادي ببكتيريا السلمونيلا بتر كيـز

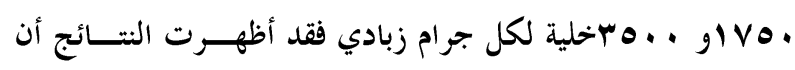

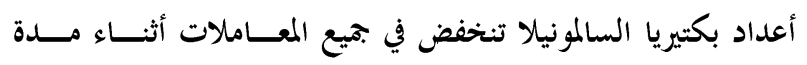

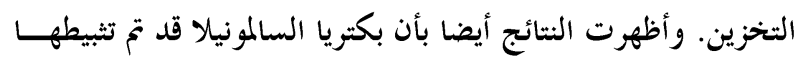

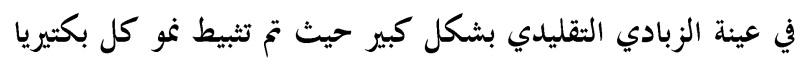

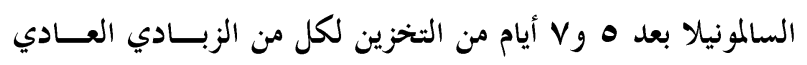

قسم علوم الغذاء والتغذية - كلية العلوم الزراعية والأغذية جامعة الملك فيصل - الهفوف-المملكة العربية السعودية mutlag1@ hotmail.com استلام البحث في r أغسطس والموافقة على النشر في بr سبتمبرى . . 
ترتفع قيم الــ (pH) للزبادي فان مستوى الحماية يصبح منخفضاً وبتالي فان الميكروبات الممرضة مثل( Listeria monocytogenes (pH) يمكن نمو ها عندما تكون قيم الــ (and Salmonella spp.

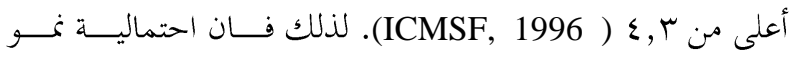
الميكروبات الممرضة في الزبادي الداعم للحيوية على (pH) أعلـى ملى

$$
\text { من ع , ع يعتبر كبيرا. }
$$

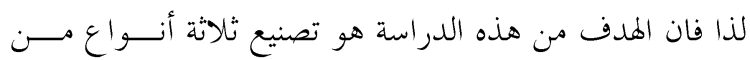

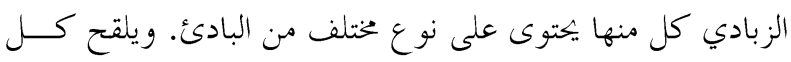

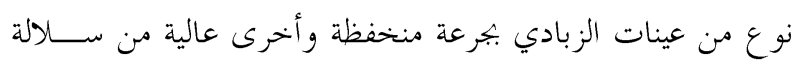

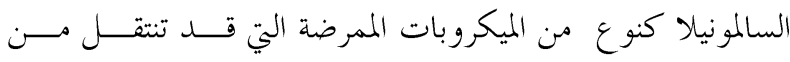

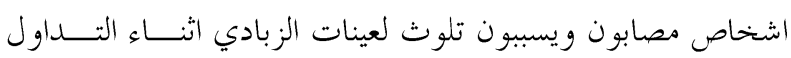

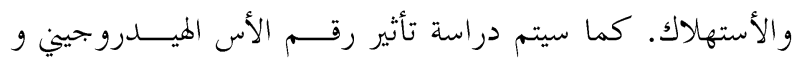
الأحماض العضوية في هذه المنتجات على سلوك بكتيريا السالمونيلا

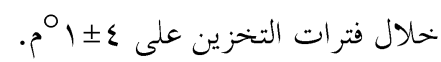

\section{الطريقـــة البحــثية}

\section{البادئات وبكتيريا السالمونيلا:}

Streptococcus يتكون بادئ الزبادي التقليدي من بكتيريــايـا thermophilus \& Lactobacillus delbrueckii subsp. بينما يتكون بــادئ الزبــادئ الــــاعم \& للحيوية الأول من بكتريا Bifidobacterium lactis (Bb-12) مين النوع الثاني يتكون من بكتريا Bifidobacterium longum

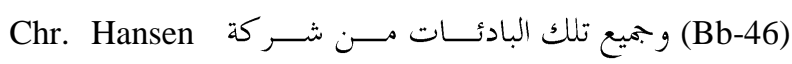
Laboratories (Copenhagen, Denmark) السالمونيلا Salmonella typhimurium فقد تم الحصول عليها من مختبر الصحة العام بالدمام( إدارة المختبرات بوزارة الصحة بالدمام، المملكة العربية السعودية).

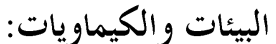

Xylose Lysine Desoxycholate Agar استخدمت بيئـة

كبيئة مناسبة لعد بكتيريا السلمونيلا ، بينما (XLD; Oxoid 469) تم الحصول على الاحماض العضوية القياسية عالية النقاوة من شركة

.(Fluka, UK)

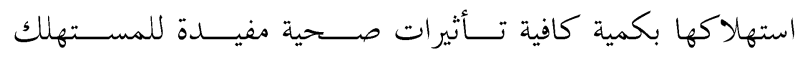
(FAO/WHO, 2001). و وتتضمن فو ائدها بحابهة العدوى البكتيرية

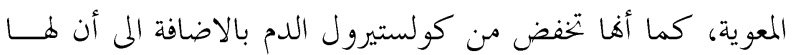

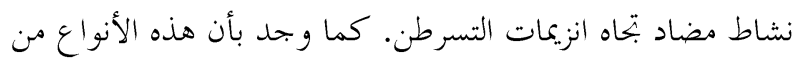

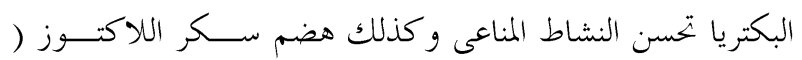

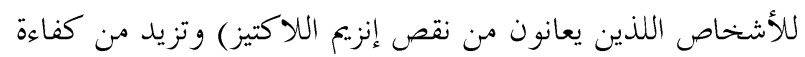
Kailaspathy \& Chin, 2000 (الهضم وامتصاص العناصر المعدنية and Schrezenmeir \& de Vrese, 2001

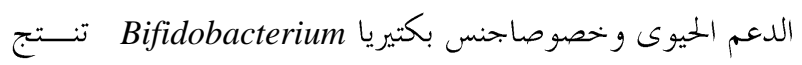

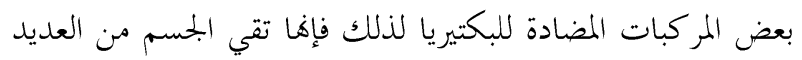

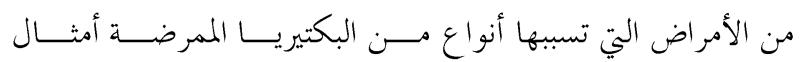
Salmonella, Shigella, Pseudomonas Helicobacter (Sgouras et al., 2004 and Servin, 2004)

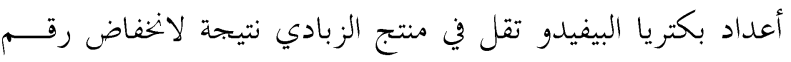

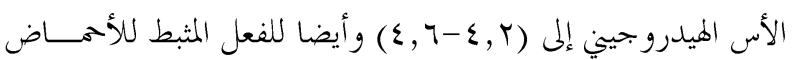

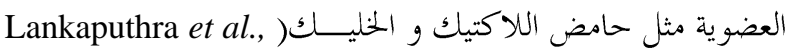
.( 1996 and El-Nemr \& Moustafa, 2007 وقد أكدت بعض نتائج الابحاث بأن أنظمـــة التــأثنير المضــــاد

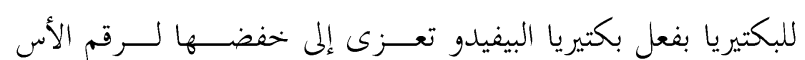

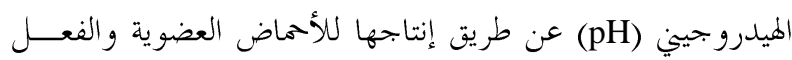

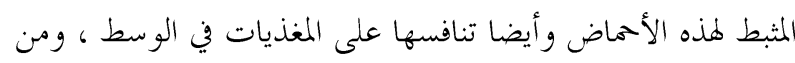

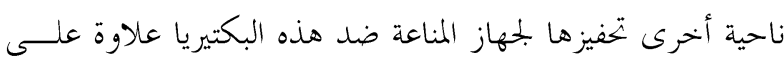

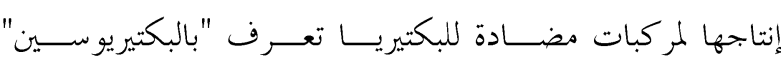
Ballongue, 1998; De Vuyst et al., 2004 and Fuller, ) 1989). والأحماض العضوية وعلى الأخص حامض اللاكتيــك و

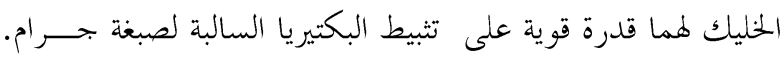

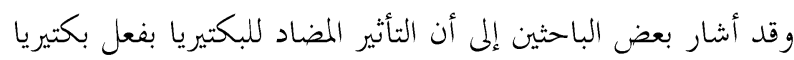

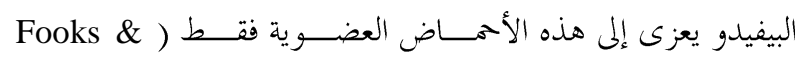
Gibson, 2002, 2003 and Ibrahim \&Bezkorovainy, .$(1993$

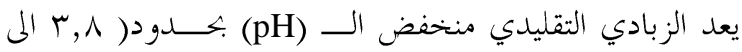

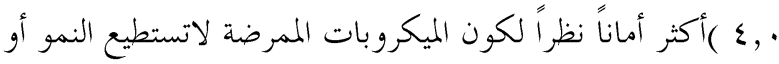

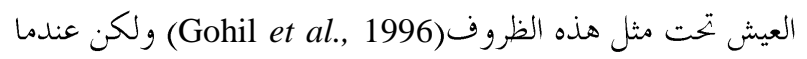




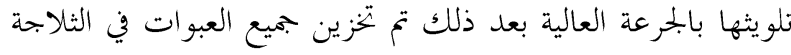
لحين إجراء التحاليل.

\section{التحاليل الطبيعية والكيميائية: الكية}

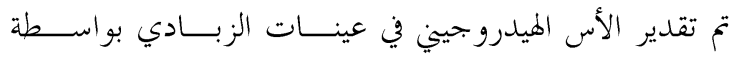

Digital pH Meter Oakton Model No. 35619

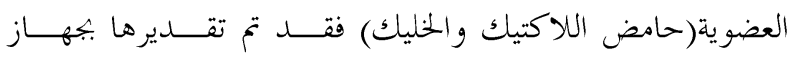

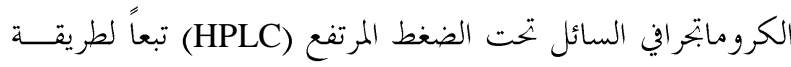

Adhikari et al. (2000)

طريقة عمل النشاط المضاد لبكتيريا السلمونيال (طريقة الانتشار من خلال القرص الورقي):

تم إضافة امل من معلق بكتيريا السالمونيلا على بيئسة الأجســار

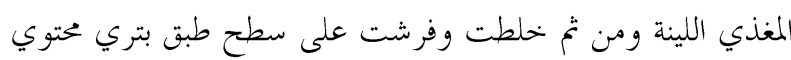
على بيئة XLD agar وتر كت لمدة ه دقائق. تم عمل طرد مركزي

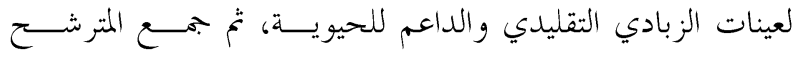

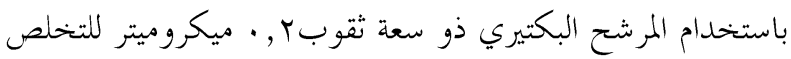

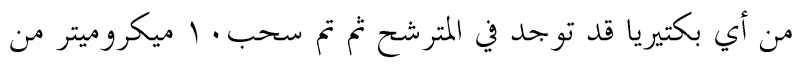

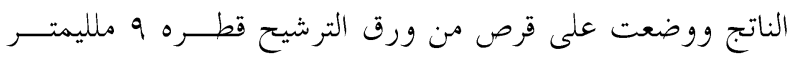

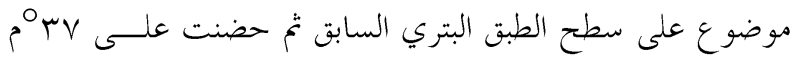
لمدة ع ب ساعة وتم قياس المنطقة الر ائقة حول القرص.

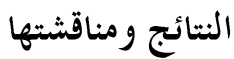

تقدير الأس الهيدروجيني والأحاض العضوية:

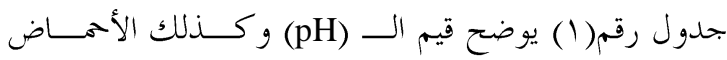

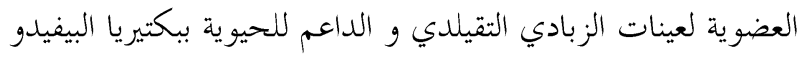

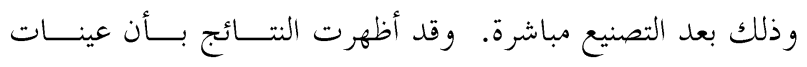

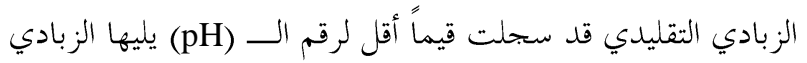

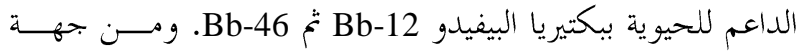

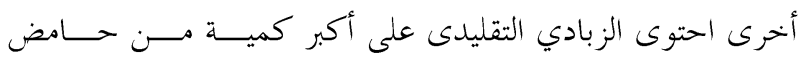

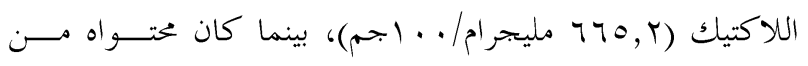

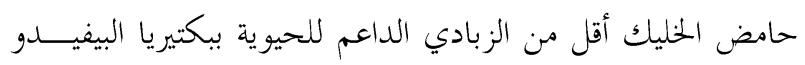

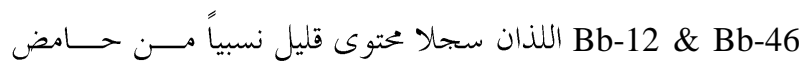
اللاكتيك مقارنة بالزبادي العادي. و قد أوضحت النتـائج بـــأن
طريقة إعداد بكتيريا السالمونيلا و تلقيح عينات الزبادي بها:

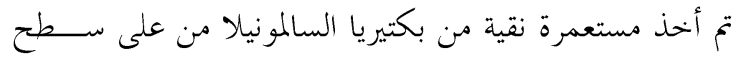

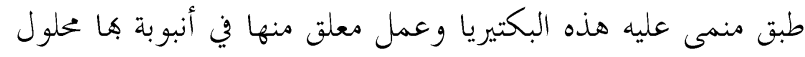
ملحي ه, , •\% وتم ضبط التركيز لإعداد بكتيريا السلمونيلا بواسطة جهاز قياس الطيف(Spectrophotometer) اعتماداً على أن القراءة

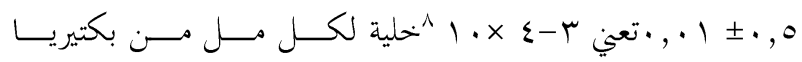

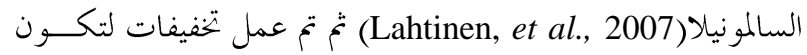
الأعداد (x · | '. ولحساب تركيز جرعة التلوث المطلوب احداثها

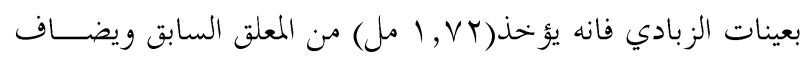

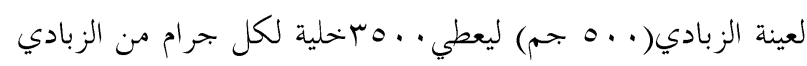

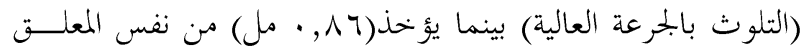

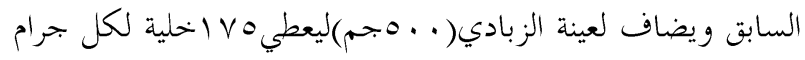
من الزبادي(التلوث بالجرعة المنخفضة).

\section{تصنيع الزبادي:}

تم الحصول على الحليب البقري المبستر من شـــركة العثمـــان

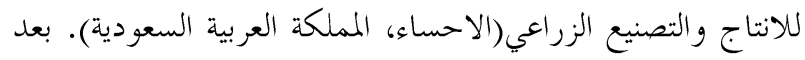

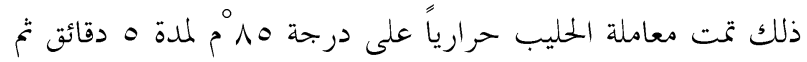

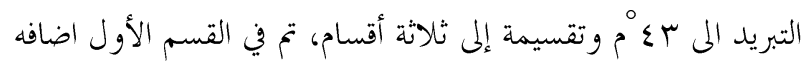
(Streptococcus thermophilus \& Lactobacillus بـــــ delbrueckii subsp. bulgaricus YC-380) وهو ما يعرف بالزبادي التقليدي. بينما في القسم الثاني أضيف بادئ

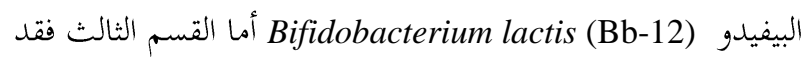
أضيف إليه بادئ البيفيــدو Bifidobacterium longum (Bb-46)

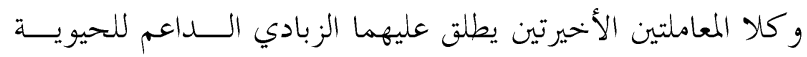

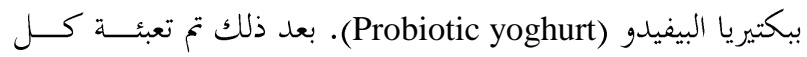

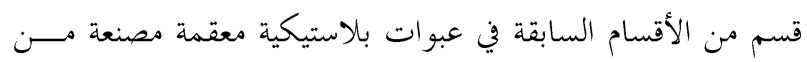

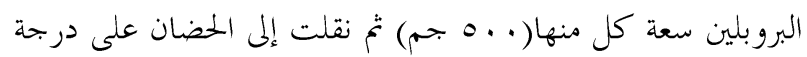

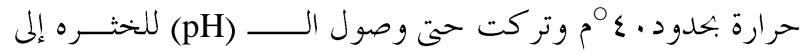

بعد ذلك قسمت عبوات كل معاملة من المعــاملات الــثلاث

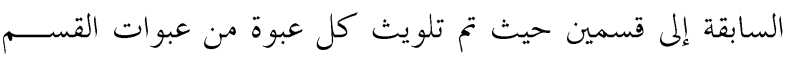

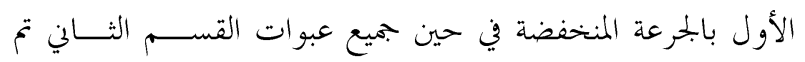


جدول Y. تأثير المترشح الناتج من الزبادي التقليدي والزبادي الداعم للحيوية ببكتيريا البيفيدو تجاه بكتيريا السالمونيلا

\begin{tabular}{|c|c|}
\hline قطر منطقة التثبيط & المعاملات \\
\hline TV & الزبادي التقليدي \\
\hline Tr & 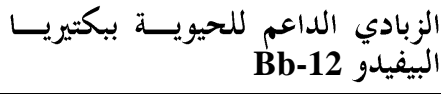 \\
\hline$r Y$ & 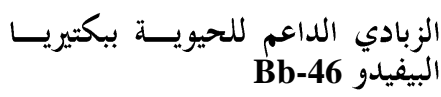 \\
\hline
\end{tabular}

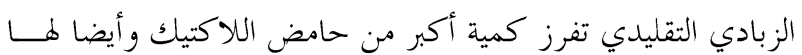

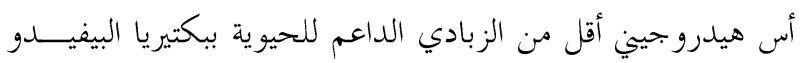

.(Arici et al., 2004)

تأثير الزبادي التقليدي و الداعم للحيوية ببكتيريا البيفيدو علــى

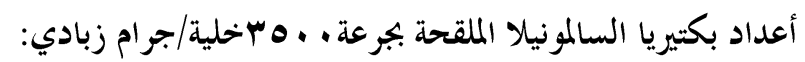
يبين الجدول رقم(r) تأثير الزبادي التقليدي والداعم للحيويسـة

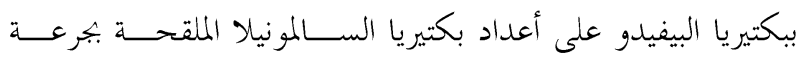

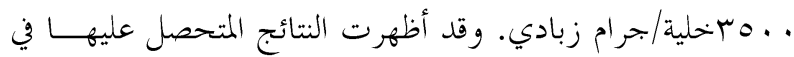

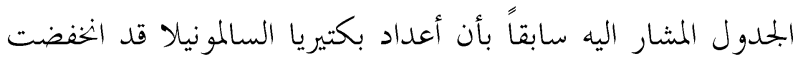

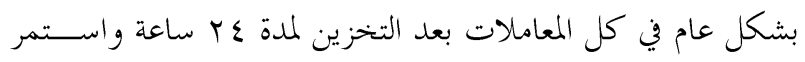
هذا الانخفاض إلي فاية فترة التخزين. وقد سجل الزبات بادي التقليدي

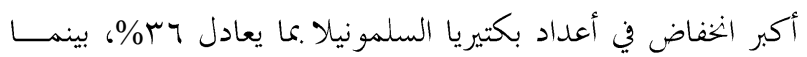

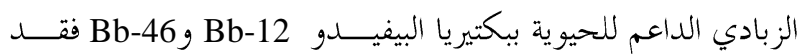

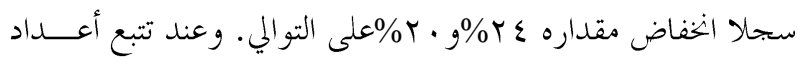

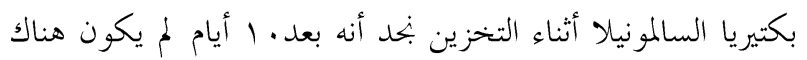

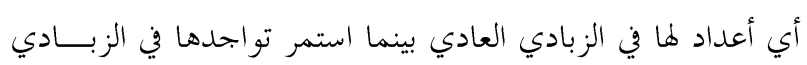

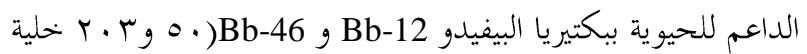
مكونة مستعمرة/جرام على التوالي) إلى فاية فترة التخزين. جدول ب. عداد بكتيريا السالمونيلا في عينات الزبادي الملقحة بجرعة . . هـ بحلية/جرام زبادي أثناء التخزين على درجة حرارة

\begin{tabular}{|c|c|c|c|c|c|c|}
\hline \multicolumn{6}{|c|}{ أعداد بكتيريا السالمونيلا (خلية مكونة للمستعمرة/جرام زبادي) } & \multirow{2}{*}{ المعاملات } \\
\hline 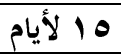 & 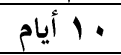 & 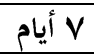 & ه أيام & 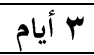 & ع Y Yاعة & \\
\hline- & - & $\varepsilon r$ & $0 \varepsilon$. & Irar & trto & 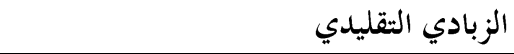 \\
\hline$\circ$. & ret & $\Lambda \cdot r$ & $\mid r \ldots$ & r... & ryo. & الزبادي الداعم للحيوية ببكتيريا البيفيـــــ-12 \\
\hline$r \cdot r$ & $\varepsilon r_{0}$ & 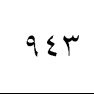 & $1 \leqslant 0$ & ro. 9 & r^.. & الزبادي الداعم للحيوية ببكتيريا البيفيـــدو \\
\hline
\end{tabular}

الزبادي الداعم للحيوية ببكتيريا البيفيدو Bb-12 أحتوى على كمية

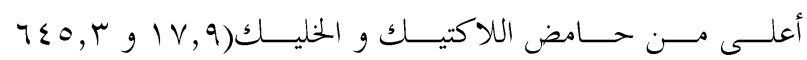

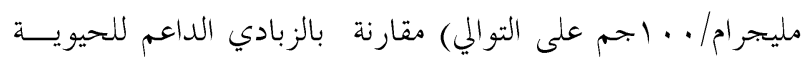

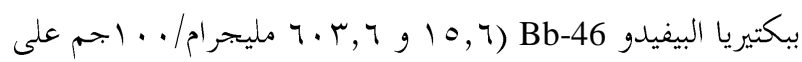

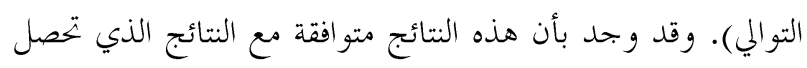

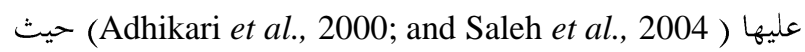
أوضحوا بأن الزبادي التقليدي يحتوي على كمية أكبر من حـــامض

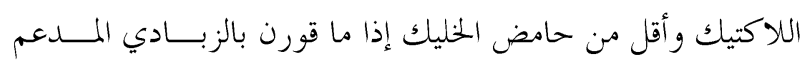
للحيوية المصنع من بكتيريا البيفيدو.

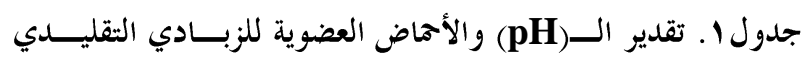

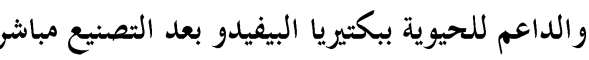

\begin{tabular}{|c|c|c|c|}
\hline \multicolumn{2}{|c|}{ الأحماض العضوية } & \multirow{3}{*}{ pH } & \multirow{3}{*}{ المعاملات } \\
\hline & (مليجر ام/. & & \\
\hline الحليك & اللاكتيك & & \\
\hline 9,9 & $770, Y$ & $\varepsilon, r q$ & الزبادي التقليدي \\
\hline $1 \vee, 9$ & $T \leqslant 0, r$ & $\varepsilon, 01$ & اليفيدوي الداعم للحيوية ببكتيريــا Bb-12 \\
\hline 10,7 & $T \cdot \Gamma, 7$ & $\varepsilon, 0 \leqslant$ & البيفيدو الزبادي الداعم للحيوية ببكتيريــا \\
\hline
\end{tabular}

النشاط المضاد لبكتيريا السلمونيلا للمترشح الناتج من الزبــادي التقليدي و الداعم للحيوية ببكتيريا البيفيدو: الجحدول رقم(r) يوضح دائرة تثبيط المترشح الناتج من الزبادي التقليدي و الداعم للحيوية ببكتيريا البيفيدو ضد بكتيريا السالمونيلا.

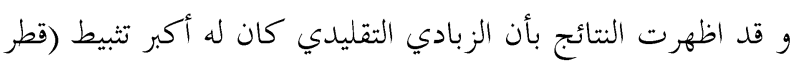
منطقة التبيطV TV ملليمتر) مقارنة بالزبادي الداعم للحيوية ببكتيريا

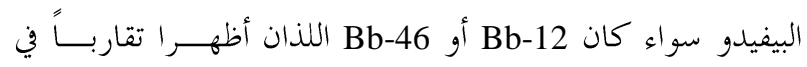

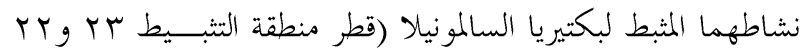
ملليمتر على التوالي)، وروبما يكون هذا التأثير راجع إلى أن بكتيريا $0, \pm \varepsilon$ 
Al-Haddad (2003) التي وجدت أن هناك علاقة بين التأثير المضاد للزبادي التقليدي والداعم للحيوية بتحاه بكتيريا السالمونيلا من جهة و الأس الهيدروجيني من جهة أخرى. كما ارجع بعض الباحثين أمثال Aroutcheva et al. (2001) اللاكتيك إلى إنتاج فوق أكسيد الهيدروجين(H

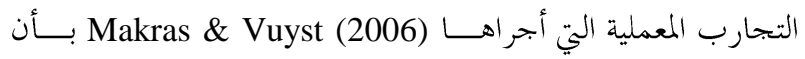
التأثير المثبط لبكتيريا البيفيدو يرجع إلى إنتاجها للاحماض العضوية.

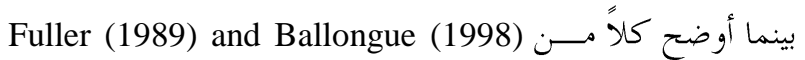

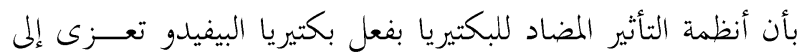
خفضها للرقم الأس الهيدروجيني(pH) عن طريق أنتاجها للأحماض العضوية خاصة اللاكتيك و الخليك حيث لمما قدرة قوية على تثبيط

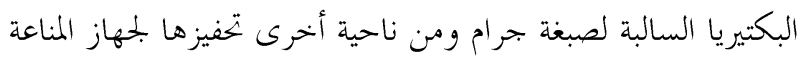

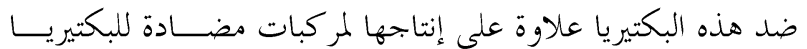
Saleh \& El-Sayed تعرف بالبكتيريوسين. وقــــــــام (2004) Bifidobacterium باستخلاص أنواع من البكتريوسين من بكتيريا و ووجــــ lactis Bb-12 \& Bifidobacterium longum Bb-46

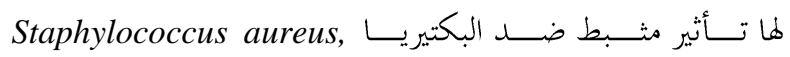
Salmonella typhimurium, Bacillus ceureus Escherichia .coli. هذا وقد أوضح (2002) بأن عينات الزبــادي المحتوية 20456 B. bifidum لها القدرة على تنبط كل من الأجناس B. وE. coli gtaph. aureusg P. aeroginosa الممرضــــ

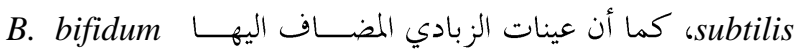

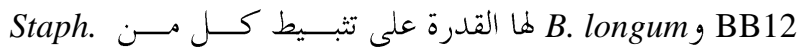
B. infants بينما العينات المضاف اليها B. subtilis و aureus
تأثيز الزبادي التقليدي و الداعم للحيوية ببكتيريا البيفيدو علــى أعداد بكتيريا السالمونيلا الملقحة بجرعة ، ه V اخلية/جرام زبادي: جدول رقم(ع) يعرض تأثير الزبادي التقليدي والداعم للحيوية

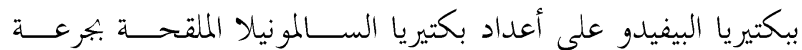

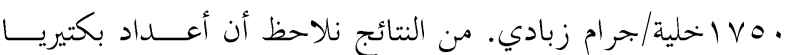
السالمونيلا قد الخفضت في جميع المعاملات بعدء ب ساعة وطوال فترة

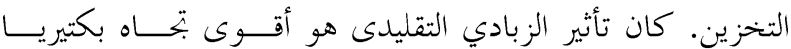
السالمونيلا بعد ع ب ساعة وخلال فترة التخزين، فقد سجل انخفاض

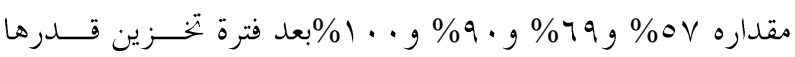

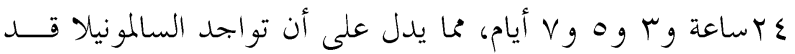

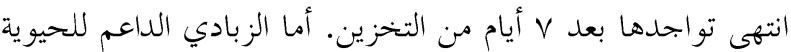
ببكتيريا البيفيدو Bb-12 فتم تثبيط بكتيريا السالمونيلا بعد · أيــام

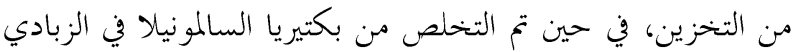
الداعم للحيوية ببكتيريا البيفيدو Bb-46 بعد ه اليوم من التخــزين.

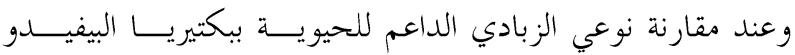
ببعضهما بند أن بكتيرياBb-12 لها نشاط مثبط لبكتيريا السالمونيلا

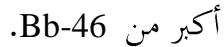
ويرجع التأثير المثبط للزبادي التقليدي و الداعم للحيوية ببكتيريا

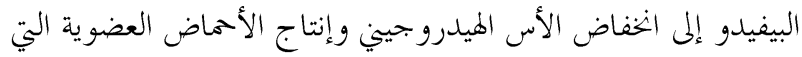

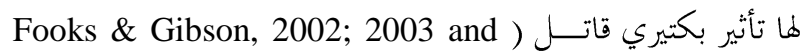
Ibrahim \& Bezkorovainy, 1993 جدول رقم(1) حيث سجل الزبادي التقليدي أقل أس هيدروجيني و أعلى كمية من حامض اللاكتيك المفرزه بينما بكتيريا البيفيـــور

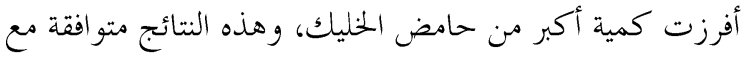

جدول ع . أعداد بكتيريا السالمونيلا في عينات الزبادي الملقحة بجرعة ه ه اخلية/جرام زبادي أثناء التخزين علي درجة حرارة

\begin{tabular}{|c|c|c|c|c|c|c|}
\hline \multicolumn{6}{|c|}{ أعداد بكتيريا السالمونيلا (خلية مكونة للمستعمرة/جر امزبادي) } & \multirow{2}{*}{ المعاملات } \\
\hline إن الأيام & 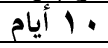 & أيام & ه أيام & 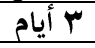 & Y Y ساعة & \\
\hline- & - & - & $1 v_{0}$ & oro & V०q & الزبادي التقليدي \\
\hline- & - & 141 & $\varepsilon 0$. & $\wedge \vee \cdot$ & $1 \cdots r$ & الزبادي الداعم للحيوية ببكتيريا البيفيدو \\
\hline- & $v$. & Yll & Or & $1 . r \Lambda$ & $1 \% \ldots$ & الزبادي الداعم للحيوية ببكتيريا البيفيدو \\
\hline
\end{tabular}


Aroutcheva, A.; Gariti, D.; Simon M.; Shott, S.; Faro, J. and Simoes, J. A. (2001). Defense factors of vaginal lactobacilli. Am Journal Obstet Gynecol. 185: 375379.

Ballongue, J. (1998). Bifidobacteria and probiotic action. In S. Salminen, and A. von Wright (Eds.), Lactic acid bacteria: microbiology and functional aspects. (2nd ed) (pp. 519-587). New York, NY, USA: Marcel Dekker, Inc.

De Vuyst, L., Avonts, L. and Makras, L. (2004). Probiotics, prebiotics and gut health. In C. Remacle, \& B. Reusens (Eds.), Functional foods, ageing and degenerative disease (1st ed) (pp. 416-482). Cambridge, UK: Woodhead Publishing Ltd.

El-Nemr, T. M. and Mostafa, H. E. (2007). Influence of Jerusalem artichoke inuline addition as a prebiotic on bifidobacteria survival in Egyptian flavored fermented "Rayeb" milk drink. Deutsche Lebensmittel Rundschau, 103, Jahrgang, heft2.

FAO/WHO (2001). Evaluation of health and nutritional properties of probiotics in food including powder milk with live lactic acid bacteria, Food and Agriculture Organization of the United Nations and World Health Organization Expert Consultation Report, Cordoba.

Fooks, L. J. and Gibson, G. R. (2002). In vitro investigations of the effect of probiotics and prebiotics on selected human intestinal pathogens. FEMS Microbiology Ecology. 39: 67-75.

Fooks, L. J. and Gibson, G. R. (2003). Mixed culture fermentation studies on the effects of symbiotic on the human intestinal pathogens Campylobacter jejuni and Escherichia coli. Anaerobe. 9: 231-242.

Fuller, R. (1989). Probiotics in man and animals. Journal of Applied Bacteriology, 66, 365-378.

Gohil, V. S.; Ahmed, M. A.; Davies, R. and Robinson, R. K. (1996). Growth and survival of Listeria monocytogenes in tow traditional food from the United Arab Emirates. Food Microbiology. 13: 159-164.

Ibrahim, S. and Bezkorovainy, A. (1993). Inhibition of Escherichia coli by bifidobacteria. Journal of Food Protection. 56: 713-715.

International Commission of Microbiological Specifications for Food (ICMSF) (1996) Salmonella. In Microorganisms in Food, pp 217264. London: Blackie Academic and Professional.

Kailaspathy K. and Chin J. (2000). Survival and therapeutic potential of probiotic organisms with
ثبطت فقط Staph. aureus. هذا وقد أظهرت كل الأنواع عـــدم و وجود فعل مثبط بتحاه كل م-ن B. cereus S. typhimurium

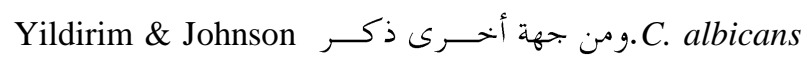

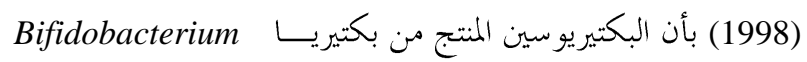
bifidum

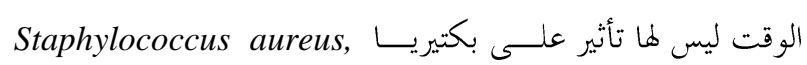
Salmonella typhimurium \& E. coli.

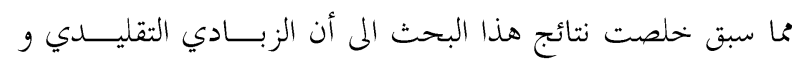

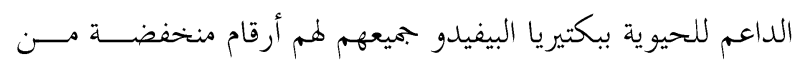

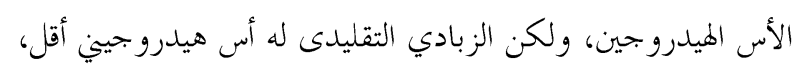

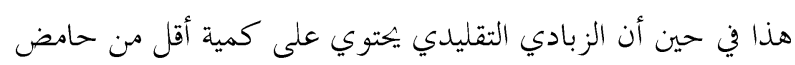

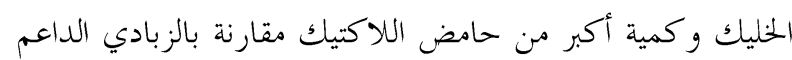

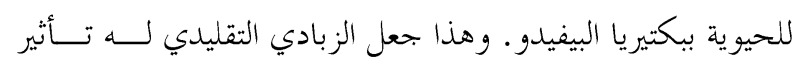

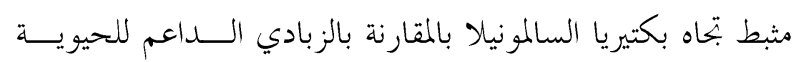

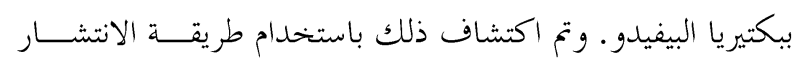

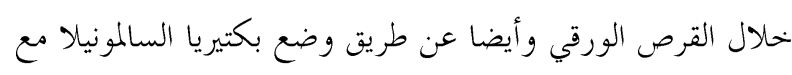

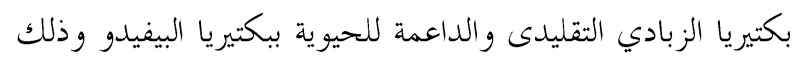

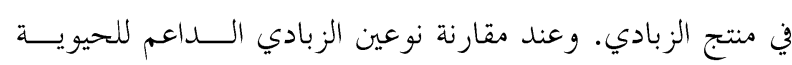

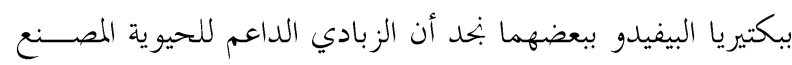

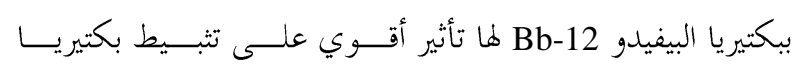

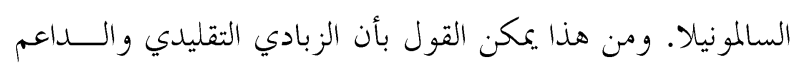

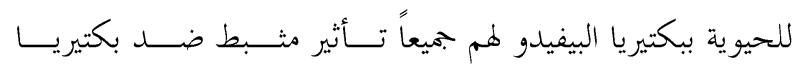
السالمونيلا.

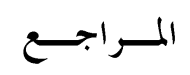

Adhikari, K.; Mustapha, A. and Grun, I. U. (2000). Viability of micro-encapsulated bifidobacteria in set yogurt during refrigerated storage. Journal of Dairy Science. 83: 1946-1951.

AL-Haddad, K. S. (2003). Survival of salmonellae in bio-yoghurt. International Journal of Dairy Technology. 56: 199-202

Arici, M.; Bilgin, B.; Sagdic, O. and Ozdemir, C. (2004). Some characteristics of Lactobacillus isolates from infant faeces. Food Microbiology. 21: 19-24. 
reference to Lactobacillus acidophilus and Bifidobacterium spp. Immunol Cell Biol. 78: 80-83.

Kheadr, E. E.; Abd-El-Rahman, M. A. and El-Nemr, T. M (2002). Survivability and antimicrobial capacity of Bifidobacteria and yoghurt bacteria during refrigerated storage of yoghurt made from lactosehydrolysed milk. Alex. Journal of Agriculture Research., 47 (2): 81-91

Lahtinen, S. J.; Jalonen, L.; Ouwehand, A. O. and Salminen, S. J. (2007). Specific Bifidobacterium strains isolated from elderly subjects inhibit growth of Staphylococcus aurous. International Journal of Food Microbiology. 117: 125-128.

Lankaputhra W. E. V.; Shah, N. P. and Britz, M. L. (1996). Survival of bifidobacteria during refrigerated storage in the presence of acid and hydrogen peroxide. Milchwissenschaft. 51: 65-70.

Makras, L. and De Vuys, L. (2006). The in vitro inhibition of Gram-negative pathogenic bacteria by bifidobacteria is caused by the production of organic acids. International Dairy Journal. 16: 1049-1057

Saleh, F. A. and El-Sayed, E. M. (2004). Isolation and characterization of bacteriocins produced by Bifidobacterium lactis $\mathrm{Bb}-12$ and Bifidobacterium longum Bb-46. The $9^{\text {th }}$ Egyptian Conference for Dairy Science \& Technology. pp 323-332.
Saleh, F. A.; Sahar, M. K. and Ibrahim, N. A. (2004). Viability and metabolic activity of microencapsulated bifidobacteria in plain and strawberry stirred yoghurt. Egyptian Journal of Agriculture Research. 82: (3), 161-175.

Schrezenmeir J. and de Vrese M. (2001). Probiotics, prebiotics, and symbiotic to approaching a definition. American Journal of Clinical Nutrition. 73 (Suppl): 361S-4S.

Servin, A. L. (2004). Antagonistic activities of lactobacilli and bifidobacteria against microbial pathogens. FEMS Microbiology Reviews. 28: 405440.

Sgouras, D.; Maragkoudakis, P.; Petraki, K.; MartinezGonzalez, B.; Eriotou, E.; Michopoulos, S.; Kalantzopoulos, G.; Tsakalidou, E. and Mentis, A. (2004). In vitro and in vivo inhibition of Helicobacter pylori by Lactobacillus casei strain Shirota. Applied and Environmental Microbiology. 70: 518-526.

Yildirim, Z. and Johnson, M. G. (1998). Characterization and antimicrobial spectrum of bifidocin B, a bacteriocin produced by Bifidobacterium bifidum NCFB 1454. J. Food Protection. 61: 47-51. 


\title{
ABSTRACT \\ Effect of Traditional Cultures of Yoghurt Starter and the Probiotic Starter Cultures of Bifidobacterium on the Pathogenic Bacterium Salmonella
}

\begin{abstract}
Al-Otaibi, Mutlag M.
The study was conducted on three samples of yoghurt, the first produced by traditional starter cultures (Streptococcus and Lactobacillus), the second by Bifidobacterium Bb-12, and the third by Bifidobacterium Bb-46. Each sample was divided into two parts and each part inoculated with Salmonella at 1750 and 350 cells per gram and stored at $4 \pm 1{ }^{\circ} \mathrm{C}$ for 15 days to determine the effect on the viability of this pathogen. The $\mathrm{pH}$ of the samples, as well as their contents of lactic and acetic acids and the counts of Salmonella were determined. The $\mathrm{pH}$ of the yoghurt produced by the traditional cultures was found to be the lowest, followed by that of the yoghurt produced by Bifidobacterium $\mathrm{Bb}-12$, and then the one produced by Bifidobacterium Bb-46. The yoghurt produced by Bifidobacterium contained more acetic acid, while the one produced by traditional cultures contained more lactic acid. Disk diffusion tests using permeate from yoghurt samples as antibiotic reveled that the

traditional culture was more inhibitory to Salmonella (clear zone diameter of $27 \mathrm{~cm}$ ) than Bb-46 and Bb-12 (clear zones diameters of 22 and 23, respectively). The counts of Salmonella decreased in all samples during storage, with more inhibition found in the traditional cultures. Complete inhibition of all Salmonella cells occurred within 5 days in traditional yoghurt samples inoculated with 1750 cells per gram and within 7 days in samples inoculated with 3500 cells per gram. Salmonella in Bb-12 and Bb-46 samples inoculated with 1750 cells per gram was completely inhibited within 10 and 15 days of storage, respectively, while the samples inoculated with 3500 cells per gram contained some viable Salmonella cells after the 15 days storage period. The study showed that both types of yoghurt, traditional or probiotic, were inhibitory to Salmonella. Traditional yoghurt had higher inhibitory effect, followed by the Bb12 and then the Bb-46 yoghurts. The inhibitory effects of these yoghurts result from their low $\mathrm{pH}$ and their high contents of the antimicrobial organic acids.
\end{abstract}

